\title{
POLAROGRAPHIC DETERMINATION OF MALONONITRILE
}

\author{
D. Ph. Zollinger, M. Bos, A. M. W. van Veen-Blaauw and W. E. van der Linden \\ Department of Chemical Technology, Twente University of Technology, P.O. Box 217, 7500 AE \\ Enschede, The Netherlands
}

(Received 11 January 1984. Accepted 5 April 1984)

\begin{abstract}
Summary-A procedure is proposed for the determination of malononitrile by differential pulse polarography in methanolic $0.1 M$ tetraethylammonium iodide $/ 0.001 M$ tetramethylammonium hydroxide as the supporting electrolyte. In this medium malononitrile is chemically converted into an electroactive species. With close control of timing of the steps in the procedure the error of the method is $\pm 1.5 \%$ in the concentration range $0.0001-0.001 \mathrm{M}$. Acrylonitrile, benzonitrile and succinic acid dinitrile do not interfere.
\end{abstract}

Malononitrile is an important compound in the technical synthesis of vitamin B1, various herbicides and insecticides, and a number of dyes. The methods described for its determination include gas chromatography, ${ }^{1}$ thin-layer chromatography, ${ }^{2}$ titration in non-aqueous solvents ${ }^{3}$ and a luminescence procedure. ${ }^{4}$ Some of these methods also apply to the assay of the riot-control agent $o$-chlorobenzal malononitrile (CS) by hydrolysis of this compound to chlorobenzaldehyde and malononitrile.,5

For CS, Tarantino ${ }^{6}$ has described a polarographic method based on the electroreduction of the compound itself or the $o$-chlorobenzaldehyde formed from it by hydrolysis. The other hydrolysis product (malononitrile) was found to be electro-inactive in his study.

We have observed that malononitrile gives rise to a polarographic reduction wave in alkaline methanolic medium. This paper describes a procedure for the polarographic determination of malononitrile based on this.

\section{EXPERIMENTAL}

\section{Reagents}

Methanol (p.a.), tetraethylammonium iodide (TEAI) (für die Polarographie), tetramethylammonium hydroxide (TMAOH) (0.1 $M$ in propan-2-ol/methanol), tetraethylammonium chloride (TEACl) (zur Synthese), lithium chloride (Suprapur), dimethylsulphoxide (zur Synthese) and ethanol (p.a.) were used as received from Merck. The malononitrile (Merck-Schuchardt, zur Synthese was recrystallized from ethanol until a colourless product was obtained. Succinic acid dinitrile (Fluka, puriss.) and benzonitrile (Riedel de Haen) were used as received. Acrylonitrile, malonic acid and cyanoacetic acid were from Fluka and used as received. The dimer of malononitrile, 2-amino-1,1,3tricyanopropene, was synthesized according to the procedure given by Carboni et al. ${ }^{7}$

\section{Apparatus}

A Metrohm E536 polarograph was used. The polarographic cell was kept at $25 \pm 0.1^{\circ}$ with a Tamson thermostat. Two mercury electrodes were used; their characteristics (open circuit in $0.1 M \mathrm{TEAI} / \mathrm{MeOH}$ ) were $m=0.795 \mathrm{mg} / \mathrm{sec}$, $t=4.73 \mathrm{sec}$ for DME \# 8 and $m=0.77 \mathrm{mg} / \mathrm{sec}, t-4.92 \mathrm{sec}$ for DME \# 5 and a mercury height of $66 \mathrm{~cm}$. The reference electrode was a silver/silver chloride electrode in methanol saturated with TEAC1. A platinum wire was used as the auxiliary electrode.

The nitrogen used for deaeration was saturated with methanol to prevent loss of solvent from the sample during removal of dissolved oxygen.

\section{Procedure}

The polarographic measurements on calibration standards and samples of malononitrile were performed as follows. A $35-\mathrm{ml}$ portion of the supporting electrolyte $(0.1 \mathrm{M}$ TEAI/0.001 $M$ TMAOH in methanol) was deaerated by passage of nitrogen for $5 \mathrm{~min}$. Then the malononitrile sample or standard was added and nitrogen was passed for $15 \mathrm{~min}$. Then either the sampled d.c. or differential pulse polarogram was recorded over the range from -1.0 to -2.0 $\mathrm{V}$ applied potential vs. silver/silver chloride (in saturated TEAC $1 / \mathrm{MeOH}$ ). The drop-time used was $0.4 \mathrm{sec}$. In the DPP technique a pulse amplitude of $20 \mathrm{mV}$ was used.

The sampled d.c. polarograms were evaluated by the use of a three-parameter curve-fitting procedure, for the parameters limiting current, half-wave potential and slope of the log plot of current $v s$. potential. ${ }^{8}$

\section{RESULTS AND DISCUSSION}

When malononitrile is polarographed in $0.1 \mathrm{M}$ TEAI $/ 0.001 M T \mathrm{TMOH} / \mathrm{MeOH}$, a reduction wave can be observed if a polarogram is run after the usual deaeration period (see Fig. 1). Its half-wave potential lies at $-1.50 \mathrm{~V} v$ s. silver/silver chloride (in saturated TEAC1/MeOH). Drop-time variation shows that this reduction wave is diffusion-controlled (Table 1). The slopes of the log plots indicate irreversibility and most likely a one-electron transfer.

The diffusion current for this reduction decreases if the alkaline solution of the malononitrile is kept for longer than $1 \mathrm{hr}$ (Table 2), presumably because of chemical conversion of the electroactive species. However, in the period 30-60 min after mixing of the malononitrile and the supporting electrolyte, the limiting current remains fairly constant.

The formation and decomposition of the electro- 
Table 1. Sampled d.c. polarography of $0.00111 \mathrm{M}$ malononitrile in $0.1 \mathrm{M}$ TEAI/0.001 $M$ TMAOH/MeOH (DME No. 5)

\begin{tabular}{ccccc}
\hline $\begin{array}{c}\text { Drop-time, } \\
\text { sec }\end{array}$ & $\begin{array}{c}\text { Limiting } \\
\text { current, } i_{\mathrm{d}}, \\
\mu A\end{array}$ & $\begin{array}{c}\text { Half-wave } \\
\text { potential, } \\
V\end{array}$ & $\begin{array}{c}\text { Slope of log } \\
\text { plot, } \\
\text { V/decade }\end{array}$ & $\begin{array}{c}i_{\mathrm{d}} / t^{1 / 6}, \\
\mu \mathrm{A} / \mathrm{sec}^{1 / 6}\end{array}$ \\
\hline 0.6 & 1.493 & -1.519 & 0.1035 & 1.63 \\
0.8 & 1.627 & -1.506 & 0.0893 & 1.69 \\
1.0 & 1.655 & -1.503 & 0.0888 & 1.66 \\
1.4 & 1.827 & -1.497 & 0.0902 & 1.69 \\
2.0 & 1.970 & -1.499 & 0.0955 & 1.76 \\
3.0 & 2.098 & -1.494 & 0.0907 & 1.75 \\
\hline
\end{tabular}

active species is strongly influenced by the concentration of TMAOH in the supporting electrolyte, as can be seen from Table 3 . If the polarograms are run about 15 min after mixing of the malononitrile and the supporting electrolyte, the optimum concentration of TMAOH is about $0.001 M$.

Malononitrile is known to form a dimer, 2-amino-1,1,3-tricyanopropene, in alkaline solutions. ${ }^{9}$ Polarography of this product, synthesized according to the procedure given by Carboni et al ${ }^{7}$ showed a reduction wave at $-1.76 \mathrm{~V}$, but not at $-1.50 \mathrm{~V}$, so this dimer cannot be the electroactive species.

Malononitrile itself is reported to be electroinactive in $0.1 \mathrm{M}$ lithium nitrate $/ \mathrm{MeOH} .{ }^{6}$ In the media $0.1 M \mathrm{NaOH} /$ water, phosphate buffer $(\mathrm{pH} 7) /$ water, $0.1 M \mathrm{LiCl} / 0.001 M$ TMAOH/DMSO and $0.1 M$ $\mathrm{LiCl} / \mathrm{MeOH}$, malononitrile is also polarographically inactive. The reduction wave at around $-1.50 \mathrm{~V}$, however, is present in polarograms of malononitrile in $0.1 M \mathrm{LiCl} / 0.001 M \mathrm{TMAOH} / \mathrm{MeOH}$ and with a

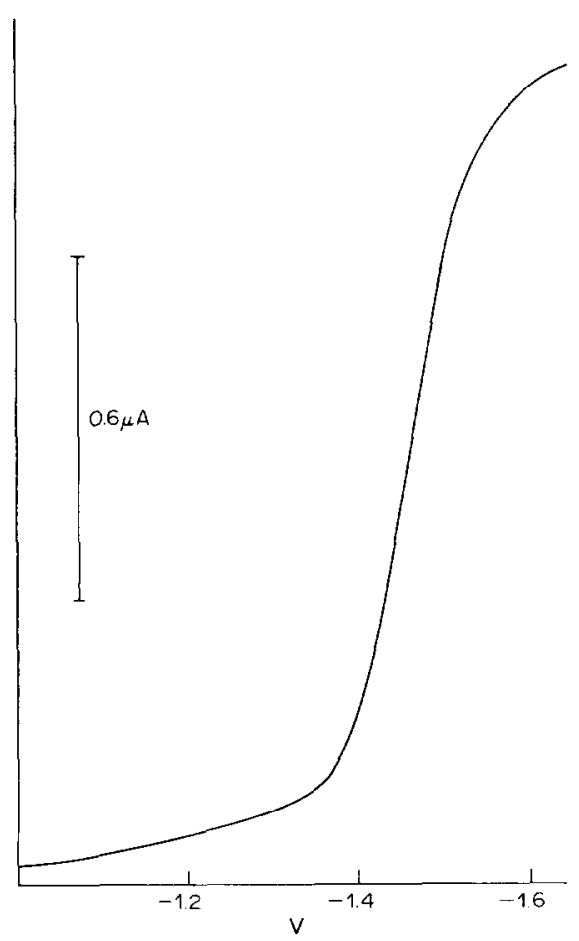

Fig. 1. Direct current polarogram of $5.35 \times 10^{-4} \mathrm{M}$ malononitrile in $0.1 \mathrm{M} \mathrm{TEAI} / 0.001 \mathrm{M} \mathrm{TMAOH} / \mathrm{MeOH}$ much smaller limiting current in $0.1 M \mathrm{LiCl} / 0.001 M$ TMAOH/EtOH.

These findings indicate that the base TMAOH and the alcoholic solvent take part in the conversion of the malononitrile into the electroactive species. This was confirmed by ultraviolet spectrometry measurements. Malononitrile shows no ultraviolet absorption in methanol. Addition of $4 \times 10^{-4} M$ TMAOH to $4.5 \times 10^{-4} \mathrm{M}$ malononitrile produces an absorption peak with a maximum shifting from 230 $\mathrm{nm}$ to $250 \mathrm{~nm}$, with substantial broadening over a period of $30 \mathrm{~min}$. Again this behaviour is different from the behaviour of the dimer, which shows a rather stable absorption peak at $300 \mathrm{~nm}$ under these conditions.

Attempts to isolate and identify this electroactive species by UV, MS and NMR spectrometry were

Table 2. Time-dependence of limiting current for $0.000535 M$ malononitrile in $0.1 M$ TEAI/0.001 $M$ $\mathrm{TMAOH} / \mathrm{MeOH}$

\begin{tabular}{cc}
\hline Time of measurement, & $\begin{array}{c}\text { Limiting current, } \\
\mu A\end{array}$ \\
\hline $\min$ & 1.193 \\
45 & 1.169 \\
60 & 1.180 \\
75 & 1.164 \\
90 & 1.150 \\
105 & 1.132 \\
120 & 1.099 \\
135 & 1.055 \\
150 & 1.008 \\
165 & 1.020 \\
180 & 0.985 \\
195 & 0.919 \\
210 & 0.949 \\
225 & 0.908 \\
\hline
\end{tabular}

Table 3. Influence of TMAOH concentration on limiting current of $0.001 M$ malononitrile in $0.1 M$

\begin{tabular}{cc}
\multicolumn{2}{c}{ TEAI/TMAOH/MeOH } \\
\hline [TMAOH], & Limiting current, \\
$m \mathrm{M}$ & $\mu A$ \\
\hline$\overline{0}$ & no reduction wave \\
0.26 & 0.198 \\
0.52 & 0.620 \\
1.04 & 1.232 \\
2.56 & 1.316 \\
5.00 & 1.030 \\
9.52 & 1.033 \\
\hline
\end{tabular}


Table 4. Calibration data for differential pulse polarography of malononitrile in $0.1 M$ TEAI/0.001 $M$ TMAOH/MeOH (DME No. 8; DPP amplitude $20 \mathrm{mV}$; $t_{\text {drop }} 0.4 \mathrm{sec}$; measurement after $15 \mathrm{~min}$ )

\begin{tabular}{ccc}
\hline $\begin{array}{c}\text { Malononitrile], } \\
10^{-4} M\end{array}$ & $\begin{array}{c}\text { Peak current } \\
\text { measured, } \\
\mu A\end{array}$ & $\begin{array}{c}\text { Peak current } \\
\text { cubic spline } \\
\text { approximation, } \\
\mu A\end{array}$ \\
\hline 0.984 & 0.570 & 0.570 \\
1.967 & 1.056 & 1.058 \\
2.951 & 1.529 & 1.519 \\
3.935 & 1.914 & 1.930 \\
4.909 & 2.294 & 2.286 \\
5.902 & 2.613 & 2.603 \\
6.886 & 2.910 & 2.925 \\
7.870 & 3.248 & 3.240 \\
8.854 & 3.426 & 3.427 \\
\hline
\end{tabular}

(Test sample: $3.84 \times 10^{-4} \mathrm{M}$ taken; peak current 1.912 $\mu \mathrm{A} \pm 0.4 \% ; 3.89 \times 10^{-4} M \pm 0.5 \%$ found; relative error $1.3 \% ; 6$ replicates).

unsuccessful, most likely because of the instability of the electroactive compound.

Nevertheless, on the basis of the findings mentioned above, it was possible to develop a procedure for the polarographic determination of malononitrile in which the parameters that influence the formation of the electroactive species are closely controlled. This was accomplished by accurate temperature control of the polarographic cell, standardization of the concentration of TMAOH in the supporting electrolyte, and a strict time schedule in the procedure.

The results for measurement of a number of standard and test solutions, prepared by directly weighing purified malononitrile and dissolving it in methanol, are given in Table 4 . The calibration graph is not linear, but the calibration data can be fitted to a cubic spline function with 3 knots equally spaced over the concentration interval measured, and this function used to retrieve the concentration of the test sample. This approach allows automation of the system. The deviation between the amount taken and found was $1.3 \%$, and the standard deviation for 6 replicate samples was $0.5 \%$

The procedure was tested for interference by the compounds cyanoacetic acid, malonic acid, acrylonitrile, benzonitrile and succinic acid dinitrile. These compounds did not change the reduction wave of the malononitrile at $-1.50 \mathrm{~V}$ when present at concentrations not exceeding that of the malononitrile.

Acknowledgement-The authors wish to thank Drs. V. W. L. J. Aarts for her helpful suggestions during this work.

\section{REFERENCES}

1. H. Binder and E. Stuerzenbecher, J. Chromatog., 1977, 130, 405.

2. H. G. Eulenhoefer, ibid., 1968, 36, 198.

3. J. S. Fritz, Anal. Chem., 1952, 34, 674.

4. U. Fritsche, Z. Anal. Chem., 1980, 302, 119.

5. S. Sass, T. L. Fisher, M. J. Jascot and J. Herban, Anal. Chem., 1971, 43, 462.

6. P. A. Tarantino and S. Sass, J. Electrochem. Soc., 1969, 116, 430.

7. R. A. Carboni, D. D. Coffman and E. G. Howard, $J$. Am. Chem. Soc., 1958, 80, 2838.

8. M. Bos, Anal. Chim. Acta, 1976, 81, 21

9. S. Bloch and G. Toupance, J. Chim. Phys., 1975, 72, 1157. 